\title{
Impact of a public campaign on pre-hospital delay in patients reporting chest pain
}

\author{
J-M Gaspoz, P-F Unger, P Urban, J-C Chevrolet, W Rutishauser, C Lovis, L Goldman, \\ C Héliot, L Séchaud, S Mischler, F A Waldvogel
}

Department of Medicine, Clinique de Médecine II, Hôpital Cantonal Universitaire, Geneva, Switzerland

$\mathrm{J}-\mathrm{M}$ Gaspoz

C Lovis

$S$ Mischler

F A Waldvogel

Department of

Medicine, Division of

Emergency Medicine,

Hôpital Cantonal

Universitaire, Geneva,

Switzerland

P-F Unger

Department of

Medicine, Division and

Centre of Cardiology,

Hôpital Cantonal

Universitaire, Geneva,

Switzerland

P Urban

W Rutishauser

Department of

Medicine, Medical

Intensive Care Unit,

Hôpital Cantonal

Universitaire, Geneva,

Switzerland

J-C Chevrolet

Department of

Medicine, University

of California, San

Francisco School of

Medicine, San

Francisco, USA

L Goldman

Department of

Nursing, Hôpital

Cantonal

Universitaire, Geneva,

Switzerland

C Héliot

School of Nursing "Le

Bon Secours",

Geneva, Switzerland

L Séchaud

Correspondence to:

Dr J-M Gaspoz, Clinique de Medicine, Hôpital Cantonal Medicine, Hopital Cantona 14, Switzerland.

Accepted for publication 26 February 1996

\begin{abstract}
Objective-To decrease pre-hospital delay in patients with chest pain.

Design-Population based, prospective observational study.

Setting-A province of Switzerland with 380000 inhabitants.
\end{abstract}

Subjects-All 1337 patients who presented with chest pain to the emergency department of the Hôpital Cantonal Universitaire of Geneva during the 12 months of a multimedia public campaign, and the 1140 patients who came with similar symptoms during the 12 months before the campaign started.

Main outcome measures-Pre-hospital time delay and number of patients admitted to the hospital for acute myocardial infarction (AMI) and unstable angina.

Results-Mean pre-hospital delay decreased from $7 \mathrm{~h} 50 \mathrm{~min}$ before the campaign to $4 \mathrm{~h} 54 \mathrm{~min}$ during it, and median delay from $180 \mathrm{~min}$ to $155 \mathrm{~min}$ $(P<0.001)$. For patients with a final diagnosis of AMI, mean delay decreased from $9 \mathrm{~h} 10 \mathrm{~min}$ to $5 \mathrm{~h} 10 \mathrm{~min}$ and median delay from $195 \mathrm{~min}$ to $155 \mathrm{~min} \quad(P<0.002)$. Emergency department visits per week for AMI and unstable angina increased from 11.2 before the campaign to 13.2 during it $(P<0.02)$, with an increase to 27 $(P<0.01)$ during the first week of the campaign; visits per week for non-cardiac chest pain increased from $7 \cdot 6$ to $8 \cdot 1(P=$ NS) during the campaign, with an increase to $17(P<0.05)$ during its first week.

Conclusions-Public campaigns may significantly reduce pre-hospital delay in patients with chest pain. Despite transient increases in emergency department visits for non-cardiac chest pain, such campaigns may significantly increase hospital visits for AMI and unstable angina and thus be cost effective.

(Heart 1996;76:150-155)

Keywords: chest pain; myocardial infarction; pre-hospital delay; public campaign

When thrombolytic therapy is administered within the first hour after the onset of symptoms of acute myocardial infarction (AMI) 35 lives can be saved per 1000 patients treated: this benefit decreases linearly after the first hour. ${ }^{1}$ If more basic, angiographic, and clinical research is needed to find the most potent and effective thrombolytic agent, ${ }^{2}$ at least as much energy should be directed to shortening the time between the onset of symptoms and treatment. ${ }^{3}$ Solutions to this problem include guidelines to shorten the time between alerting the medical or the ambulance services and their intervention, ${ }^{34}$ pre-hospital thrombolysis, ${ }^{5-9}$ and fast-track assessments in the emergency departments. ${ }^{41011}$

These efforts, however, are weakened by patient delay, which may account for almost two thirds of the time from the onset of symptoms to treatment. ${ }^{34}$ In 1991-92, in the canton (province) of Geneva, Switzerland, mean and median pre-hospital delays were still $10 \mathrm{~h} 02 \mathrm{~min}$ and $2 \mathrm{~h} 55 \mathrm{~min}$, respectively, in patients with symptoms of AMI. ${ }^{12}$

The results of public education campaigns to reduce patient delay have been mixed. ${ }^{13-21}$ With the support of the health authorities of the canton of Geneva, we decided to launch and evaluate an intense public campaign focusing on chest pain in an effort to decrease pre-hospital delays in such patients.

\section{Patients and methods}

The canton of Geneva is an urban area (282 $\mathrm{km}^{2}$ ) of Switzerland, with 380000 inhabitants and with Geneva as its capital. The Hôpital Cantonal Universitaire is the major hospital (1459 beds) of the canton, as well as its only public, and teaching, hospital. Out-of-hospital services for medical emergencies include: the hospital-based central switchboard for medical emergencies (telephone number 144), which can send a physician-staffed mobile intensive care unit; private ambulance companies with paramedics trained in resuscitation; private services for emergency home medical visits; private walk-in clinics; and private practitioners.

\section{THE CAMPAIGN}

The public

A 12 month multimedia public campaign with the slogan "Heart attack? Every minute counts! Call 144!" was launched on 5 October 1992. Information on chest pain, AMI, and thrombolysis, was broadcast during the midday and evening news on the public TV network of the French speaking part of Switzerland on day 1 and six months later. There were also four $30 \mathrm{~min}$ TV shows three and five months later and a 30 second cartoon on chest pain, ending with a special logo for the campaign, was broadcast on TV 14 times per month for 12 months. 
The public radio of the French speaking part of Switzerland broadcast information during the midday and evening news on day 1 and six months later and there was a 45 min programme on the campaign on day 1. Private radio broadcast 30 second messages six times a day during three separate weeks, six months after the beginning of the campaign.

A press conference with the minister of health of the canton was held on day 1 ; this was widely reported in the newspapers. Advertisements carrying the logo of the campaign and its slogan appeared in the newspapers twice a week for 12 months. Posters were put up in the street and on buses and trams for seven two week periods. Leaflets were distributed to households living outside the town, to all senior citizens, and to all state and town employees with one of their paychecks; to patients and visitors at the hospital for 12 months; in all post offices and pharmacies in the canton; and in the major supermarkets for two periods of two weeks.

Patients at risk and out-of-hospital services Leaflets were distributed to all patients admitted to the hospital for suspected AMI and to patients following rehabilitation programmes after an AMI. They were mailed to out-ofhospital public and private nursing services and to all medical practitioners, those who lecture to paramedics, policemen, and private and hospital physicians.

ANALYSIS

The impact of the campaign was evaluated by

Table 1 Clinical characteristics

\begin{tabular}{lccl}
\hline Characteristics & $\begin{array}{l}\text { Phase I } \\
(n=1100)\end{array}$ & $\begin{array}{l}\text { Phase II } \\
(n=1295)\end{array}$ & \\
\hline Male sex & $697(63 \%)$ & $795(61 \%)$ & $\mathrm{P}=\mathrm{NS}$ \\
Age (SD) (yr) & $62(16)$ & $64(16)$ & $\mathrm{P}<0 \cdot 02$ \\
Resident & $1029(94 \%)$ & $1209(93 \%)$ & $\mathrm{P}=\mathrm{NS}$ \\
Hypertension & $416(38 \%)$ & $550(42 \%)$ & $\mathrm{P}<0 \cdot 03$ \\
Diabetes & $162(15 \%)$ & $193(15 \%)$ & $\mathrm{P}=\mathrm{NS}$ \\
Past history of: & $263(24 \%)$ & $286(22 \%)$ & $\mathrm{P}=\mathrm{NS}$ \\
$\quad$ Myocardial infarction & $240(22 \%)$ & $345(27 \%)$ & $\mathrm{P}<0.01$ \\
$\quad$ Angina & $159(14 \%)$ & $189(15 \%)$ & $\mathrm{P}=\mathrm{NS}$ \\
$\quad$ PTCA/CABG & $727(66 \%)$ & $792(61 \%)$ & $\mathrm{P}<0.03$ \\
\hline Typical chest pain & & & \\
\hline
\end{tabular}
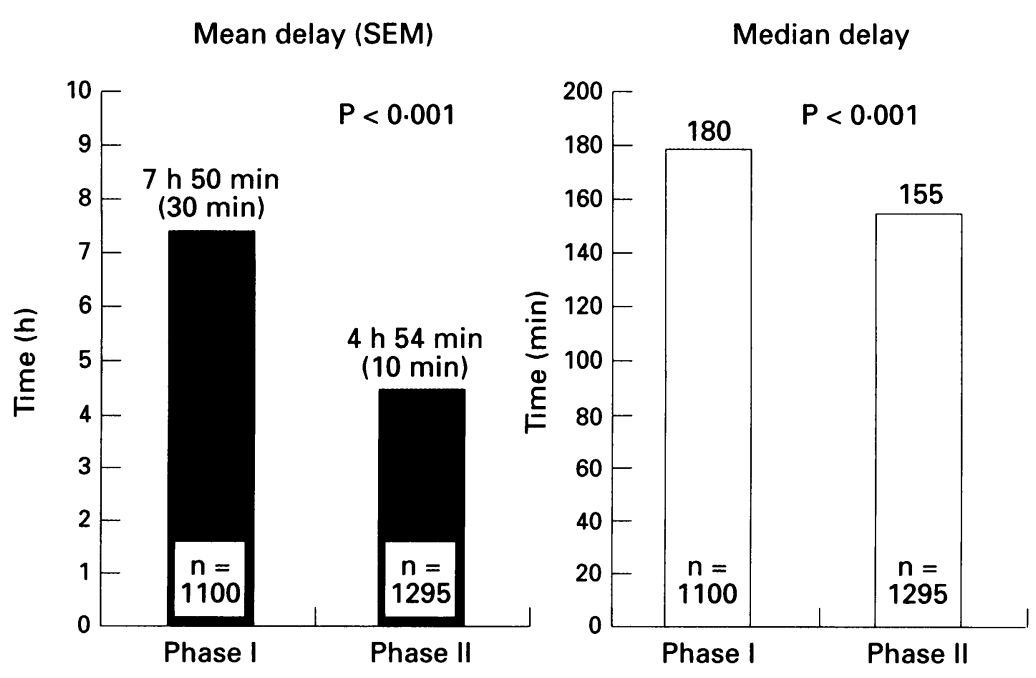

Impact of the campaign on mean and median pre-hospital delays in chest pain patients. Phase I, the 12 months before the campaign; phase II, the 12 months of the campaign. means of a prospective observational study with two phases: a 12 month pre-campaign period and a 12 month campaign period.

\section{Patient population and data collection}

For all patients who presented with chest pain to the emergency department of the Hopital Cantonal Universitaire during the 12 months before the campaign and during the 12 months of the campaign, data were prospectively collected by research nurses through interviews with the patients or their relatives; review of the medical, nursing, and administrative records; review of the records of the central switchboard for medical emergencies and of ambulance companies; and through information obtained from the private services that dealt with emergency home medical visits.

\section{Clinical outcomes}

Status on discharge, as well as final diagnoses, were obtained for all 1140 and 1337 patients who came to the emergency department with chest pain during the 12 months before the campaign and the 12 months of the campaign respectively. A final diagnosis of AMI was based on the standard World Health Organisation criteria for clinical history and the results of electrocardiography and cardiac enzyme tests. ${ }^{22}$ A final diagnosis of unstable angina was made according to Braunwald's definition. ${ }^{23}$ Detailed information on pre-hospital delays were available for $1100 / 1140$ (96.5\%) chest pain patients during the precampaign period and for $1295 / 1337(96.9 \%)$ patients during the campaign period $(\mathbf{P}=$ NS).

\section{Statistical analysis}

A chi-squared test was used to compare categorical variables and Student's $t$ test for continuous variables. Time intervals were not normally distributed and were analysed by means of the Wilcoxon rank sum test. All tests were two-sided and regarded as significant if $\mathrm{P}<0.05$.

\section{Results}

\section{CLINICAL CHARACTERISTICS}

The clinical characteristics of the 1100 chest pain patients who presented to the emergency department during the 12 months before the campaign (phase I) and for whom information was obtained are listed in table 1 and are compared with the characteristics of the 1295 patients who presented to the emergency department during the 12 months of the campaign (phase II) and for whom information was obtained.

\section{PRE-HOSPITAL DELAY}

\section{All patients}

Mean and median pre-hospital delays were significantly reduced during the campaign by $2 \mathrm{~h} 56 \mathrm{~min}$ and $25 \mathrm{~min}$ respectively $(\mathrm{P}<0.001$ ) (fig). During the first three months of the campaign, only mean prehospital delay was reduced, without any effect on median delay, which was consistent with a 
Table 2 Pre-hospital delays: variation by three months intervals

\begin{tabular}{|c|c|c|c|c|c|}
\hline & \multirow{2}{*}{$\begin{array}{l}\text { Phase I } \\
(n=1100)\end{array}$} & $\begin{array}{l}\text { Phase II (mnth) } \\
1-3\end{array}$ & $4-6$ & $7-9$ & $10-12$ \\
\hline & & $(n=336)$ & $(n=351)$ & $(n=302)$ & $(n=306)$ \\
\hline $\begin{array}{l}\text { Mean (SEM) } \\
\text { Median } \\
\text { P value }\end{array}$ & $\begin{array}{l}7 \mathrm{~h} 50 \min (30 \mathrm{~min}) \\
180 \mathrm{~min}\end{array}$ & $\begin{array}{l}5 \mathrm{~h} 57 \mathrm{~min}(25 \mathrm{~min}) \\
180 \mathrm{~min} \\
\mathrm{NS}\end{array}$ & $\begin{array}{l}4 \mathrm{~h} 33 \min (18 \mathrm{~min}) \\
145 \mathrm{~min} \\
0.001\end{array}$ & $\begin{array}{l}4 \mathrm{~h} 35 \mathrm{~min}(21 \mathrm{~min}) \\
158 \mathrm{~min} \\
0.02\end{array}$ & $\begin{array}{l}4 \mathrm{~h} 27 \mathrm{~min}(19 \mathrm{~min}) \\
143.5 \mathrm{~min} \\
0.002\end{array}$ \\
\hline
\end{tabular}

Table 3 Components of the pre-hospital delay

\begin{tabular}{|c|c|c|c|c|}
\hline Component & $\begin{array}{l}\text { Phase I } \\
(n=855)\end{array}$ & $\begin{array}{l}\text { Phase II } \\
(n=961)\end{array}$ & & \\
\hline $\begin{array}{l}\text { Total pre-hospital delay: } \\
\text { Mean (SEM) } \\
\text { Median }\end{array}$ & $\begin{array}{l}8 \text { h } 38 \min (38 \mathrm{~min}) \\
190 \mathrm{~min}\end{array}$ & $\begin{array}{l}5 \mathrm{~h} 16 \mathrm{~min}(13 \mathrm{~min}) \\
161.5 \mathrm{~min}\end{array}$ & $P<0.002$ & \\
\hline $\begin{array}{l}\text { Delay from onset of symptoms to alert: } \\
\text { Mean (SEM) } \\
\text { Median }\end{array}$ & $\begin{array}{l}4 \mathrm{~h} 47 \mathrm{~min}(21 \mathrm{~min}) \\
86.5 \mathrm{~min}\end{array}$ & $\begin{array}{l}3 \mathrm{~h} 02 \mathrm{~min}(10 \mathrm{~min}) \\
60 \mathrm{~min}\end{array}$ & $P<0.001$ & \\
\hline $\begin{array}{l}\text { Delay from alert to arrival at the hospital: } \\
\text { Mean (SEM) } \\
\text { Median }\end{array}$ & $\begin{array}{l}3 \mathrm{~h} 52 \mathrm{~min}(30 \mathrm{~min}) \\
80 \mathrm{~min}\end{array}$ & $\begin{array}{l}2 \mathrm{~h} 14 \mathrm{~min}(8 \mathrm{~min}) \\
70.5 \mathrm{~min}\end{array}$ & $P<0.05$ & $P<0.05$ \\
\hline
\end{tabular}

predominant effect on outliers with long delays (table 2). During the subsequent three months intervals of the campaign, both mean and median delays were significantly reduced.

The components of pre-hospital delay were examined during the pre-campaign and the campaign periods for the $855(78 \%)$ and 961 (74\%) patients who alerted out-of-hospital medical or paramedical services respectively before coming to the hospital. For these patients, mean and median pre-hospital delays were reduced by $3 \mathrm{~h} 22 \mathrm{~min}$ and $28.5 \mathrm{~min}$ respectively $(P<0.002)$ (table 3$)$. The reduction in the delay between the onset of symptoms and the alert of any out-of-hospital service was significantly greater $(P<0.05)$ than the reduction in the delay between the time of the alert and arrival at the hospital, suggesting that the campaign had more impact on the patients than on the out-of-hospital services.

\section{Subgroup analyses}

Mean and median pre-hospital delays were significantly reduced during the campaign for patients with a final diagnosis of AMI, and the reduction of these delays almost reached statistical significance for patients with unstable angina (table 4). Although some shortening of mean pre-hospital delays was observed for patients with a final diagnosis of cardiac diseases other than AMI and unstable angina, such as acute pericarditis, acute congestive heart failure, and stable angina, as well as for patients with a final diagnosis of non-cardiac diseases, no significant reduction of their prehospital delays occurred, as is reflected by minimal or no change in their median delays.

Table 4 Pre-hospital delay: subgroup analyses

\begin{tabular}{|c|c|c|c|}
\hline Diagnosis & Phase I & Phase II & $P$ \\
\hline \multicolumn{4}{|c|}{ Acute myocardial infarction: } \\
\hline Number & 309 & 341 & \\
\hline Mean (SEM) & $9 \mathrm{~h} 10 \mathrm{~min}(67 \mathrm{~min})$ & $5 \mathrm{~h} 10 \mathrm{~min}(21 \mathrm{~min})$ & \\
\hline Median & $195 \mathrm{~min}$ & $155 \mathrm{~min}$ & $<0.002$ \\
\hline \multicolumn{4}{|l|}{ Unstable angina: } \\
\hline Number & 257 & 327 & \\
\hline Mean & $7 \mathrm{~h} 52 \mathrm{~min}(51 \mathrm{~min})$ & $4 \mathrm{~h} 46 \mathrm{~min}(20 \mathrm{~min})$ & \\
\hline Median & $200 \mathrm{~min}$ & $160 \mathrm{~min}$ & $<0.06$ \\
\hline \multicolumn{4}{|l|}{ Other cardiac diseases: } \\
\hline $\begin{array}{l}\text { Number } \\
\text { Mean (SEM) }\end{array}$ & $\begin{array}{l}164 \\
8 \mathrm{~h} 21 \mathrm{~min}(116 \mathrm{~min})\end{array}$ & $\begin{array}{l}225 \\
4 \mathrm{~h} 27 \mathrm{~min}(21 \mathrm{~min})\end{array}$ & \\
\hline Median & $150 \mathrm{~min}$ & $150 \mathrm{~min}$ & NS \\
\hline \multicolumn{4}{|c|}{ Other non-cardiac diseases: } \\
\hline $\begin{array}{l}\text { Number } \\
\text { Mean (SEM) }\end{array}$ & $\begin{array}{l}370 \\
6 \mathrm{~h} 27 \mathrm{~min}(34 \mathrm{~min})\end{array}$ & $\begin{array}{l}402 \\
5 \mathrm{~h} 01 \mathrm{~min}(20 \mathrm{~min})\end{array}$ & \\
\hline Median & $169.5 \mathrm{~min}$ & $150 \mathrm{~min}$ & NS \\
\hline $\begin{array}{l}\text { Age and gender: } \\
<75 \text { years old } \\
\text { Men }\end{array}$ & & & \\
\hline Number & 574 & 638 & \\
\hline Mean (SEM) & $8 \mathrm{~h} 16 \mathrm{~min}(50 \mathrm{~min})$ & 4 h $49 \min (16 \min )$ & \\
\hline Median & $168 \mathrm{~min}$ & $139.5 \mathrm{~min}$ & $<0.001$ \\
\hline \multicolumn{4}{|l|}{ Women } \\
\hline $\begin{array}{l}\text { Number } \\
\text { Mean (SEM) }\end{array}$ & 228 & 253 & \\
\hline $\begin{array}{l}\text { Mean (SEM) } \\
\text { Median }\end{array}$ & $\begin{array}{l}6 \mathrm{~h} 26 \mathrm{~min}(45 \mathrm{~min}) \\
165 \mathrm{~min}\end{array}$ & $\begin{array}{l}5 \mathrm{~h} 14 \mathrm{~min}(26 \mathrm{~min}) \\
165 \mathrm{~min}\end{array}$ & NS \\
\hline \multirow{2}{*}{\multicolumn{4}{|c|}{$\begin{array}{l}\text { Age and gender: } \\
\geqslant 75 \text { years old }\end{array}$}} \\
\hline & & & \\
\hline Number & & 157 & \\
\hline Mean (SEM) & $6 \mathrm{~h} 58 \mathrm{~min}(49 \mathrm{~min})$ & $4 \mathrm{~h} 26 \mathrm{~min}(20 \mathrm{~min})$ & \\
\hline Median & $220 \mathrm{~min}$ & $150 \mathrm{~min}$ & $<0.02$ \\
\hline \multicolumn{4}{|l|}{ Women } \\
\hline Number & 175 & 247 & \\
\hline $\begin{array}{l}\text { Mean (SEM) } \\
\text { Median }\end{array}$ & $\begin{array}{l}8 \mathrm{~h} 48 \mathrm{~min}(71 \mathrm{~min}) \\
201 \mathrm{~min}\end{array}$ & $\begin{array}{l}5 \mathrm{~h} 04 \mathrm{~min}(23 \mathrm{~min}) \\
189 \mathrm{~min}\end{array}$ & NS \\
\hline
\end{tabular}


Table 5 Cumulative mean number of emergency room visits per week overall and by diagnosis

\begin{tabular}{|c|c|c|c|c|c|}
\hline & \multirow[b]{2}{*}{ Phase I } & \multicolumn{4}{|l|}{ Phase II } \\
\hline & & First week & 1 month & 6 months & 12 months \\
\hline All patients & $22 \cdot 2$ & $49 \star \star \star$ & $29 \cdot 4$ & $27 \cdot 5^{\star \star \star \star}$ & $26^{\star \star \star \star}$ \\
\hline $\begin{array}{l}\text { Acute myocardial infarction } \\
\text { and unstable angina } \\
\text { Other cardiac diseases } \\
\text { Other non-cardiac diseases }\end{array}$ & $\begin{array}{r}11 \cdot 2 \\
3 \cdot 4 \\
7 \cdot 6\end{array}$ & $\begin{array}{l}27^{\star \star \star} \\
5 \\
17^{\star}\end{array}$ & $\begin{array}{c}14.5 \\
4 \cdot 9 \\
10\end{array}$ & $\begin{array}{c}13 \cdot 3^{\star \star} \\
4 \cdot 8 \\
9 \cdot 4\end{array}$ & $\begin{array}{c}13 \cdot 2^{\star \star} \\
4 \cdot 7 \\
8 \cdot 1\end{array}$ \\
\hline
\end{tabular}

Pre-hospital delays were significantly reduced for men but not for women. For men, pre-hospital delays were significantly reduced, irrespective of age, although the magnitude for the reduction in median delays was more marked for men aged 75 or older.

THROMBOLYSIS RATES, TIME TO

THROMBOLYSIS, AND CLINICAL OUTCOMES

During the pre-campaign period and during the campaign, respectively, 82/314 (26.1\%) and $105 / 346(30 \cdot 3 \%)$ patients with AMI underwent thrombolysis on admission; during the same periods, respectively, $10 / 314(3 \cdot 2 \%)$ and $15 / 346(4 \cdot 3 \%)$ patients with AMI underwent primary percutaneous transluminal angioplasty (PTCA). Thus 92/314 (29.3\%) AMI patients underwent thrombolysis or primary PTCA during the 12 months before the campaign, whereas $20 / 346(34 \cdot 7 \%)$ underwent these procedures during the 12 months of the campaign ( $P=N S$ ). Mortality from AMI went down from $15 \%$ before the campaign to $12 \%$ during it $(\mathrm{P}=\mathrm{NS})$.

For patients who underwent thrombolysis, time to treatment was reduced by the campaign: mean and median "onset to needle" times decreased from $3 \mathrm{~h} 32 \mathrm{~min}$ and $3 \mathrm{~h} 20$ min to $3 \mathrm{~h} 18 \mathrm{~min}$ and $2 \mathrm{~h} 45 \mathrm{~min}$ respectively $(\mathrm{P}<0.05)$; mean and median "call to needle" times decreased from $2 \mathrm{~h} 25 \mathrm{~min}$ and $2 \mathrm{~h} 07$ $\min$ to $2 \mathrm{~h} 06 \mathrm{~min}$ and $1 \mathrm{~h} 42 \mathrm{~min}$ respectively $(\mathrm{P}<0.01)$; mean and median-"door to needle" times decreased from $59 \mathrm{~min}$ and $45 \mathrm{~min}$ to $52 \mathrm{~min}$ and $35 \mathrm{~min}$ respectively $(P=0.07)$.

\section{CALLS TO THE CENTRAL SWITCHBOARD FOR} MEDICAL EMERGENCIES, AMBULANCE USE, AND HOSPITAL VISITS FOR AMI AND UNSTABLE ANGINA

During the campaign, 256/1295 (20\%) patients called the central switchboard for medical emergencies as the first alert, as compared with $138 / 1100$ (13\%) before the campaign $(\mathrm{P}<0.001)$. However, ambulance use was not significantly affected: $684 / 1295(53 \%)$ patients came to the hospital by ambulance during the campaign compared with 563/1100 $(51 \%)$ before it $(\mathrm{P}=\mathrm{NS})$.

During the first week of the campaign, emergency department visits for chest pain increased to 49 , as compared with an average of $22 \cdot 2$ visits per week during the preceding 12 months $(P<0.01)$ (table 5$)$. This increase in emergency department visits remained significant at six and 12 months. Emergency department visits for all medical or surgical conditions other than chest pain increased from 53227 during the 12 months before the campaign to 56436 during it; this $6 \%$ increase was significantly smaller than the $17 \cdot 3 \%$ (from 1140 to 1337 ) increase observed in visits for chest pain $(\mathrm{P}<0.03)$.

The increase of emergency department visits for chest pain during the first week was the result of a more than twofold increase in visits for AMI and unstable angina $(P<0.01)$ and visits for chest pain of non-cardiac origin $(P<0.05)$. Visits due to cardiac diseases other than AMI and unstable angina increased only slightly $(P=N S)$. At six and 12 months the increase in emergency department visits per week for AMI and unstable angina was still significant, whereas it was not significant for visits owing to non-cardiac chest pain.

\section{COSTS OF THE CAMPAIGN}

Costs related to the campaign itself (TV, radio, newspaper advertisements, posters, and leaflets) totalled $\mathrm{Sw}$ fr 300000 ( $£ 150000)$ which for a population of 380000 inhabitants is $\mathrm{Sw}$ fr $0.80(£ 0.40)$ per inhabitant.

The indirect costs of the campaign are more difficult to evaluate. Although not all of the emergency department visits and hospital admissions for chest pain of non-cardiac origin will have been inappropriate, they could be used as an indicator of an unnecessary increase in the use of hospital resources related to the campaign. Emergency department visits for non-cardiac chest pain increased from 390 during the 12 months before the campaign to 416 during the 12 months of the campaign, an increase of $26(6.7 \%)$ visits. Of the 416 patients who came to the emergency department with chest pain of non-cardiac origin during the campaign, $153(37 \%)$ were admitted to the hospital compared with 144 out of 390 (37\%; P = NS) such patients before the campaign, an increase in nine $(6 \cdot 2 \%)$ admissions.

\section{Discussion}

This study showed a significant reduction during a 12 month public campaign in pre-hospital delays in patients with chest pain. It confirmed the findings of Herlitz et al ${ }^{18}{ }^{19}$ by showing that public campaigns can significantly shorten pre-hospital delays in patients with AMI. However, our study examined the impact of a public campaign on all patients who came to an emergency department with chest pain; it showed that the impact of the campaign on pre-hospital delays was very strong for patients 
with final diagnoses of AMI or unstable angina, but was much weaker for patients with chest pain of other causes, possibly because such patients already had short pre-hospital delays before the campaign. The impact on men was significant for all ages, although more so for men aged 75 or more, as their delays were particularly long before the campaign. Women seemed less affected by the campaign, possibly because we had targeted our TV advertisements more on men.

The major difference between our study and the previous ones ${ }^{13-21}$ was that emergency department visits for AMI and unstable angina increased abruptly during the first week of the campaign, and remained significantly increased during the year of the campaign. On the other hand, emergency department visits for chest pain of non-cardiac origin increased transiently and were not significantly increased throughout the whole campaign period. One explanation may be the frequent repetition of the TV cartoons, which gave us the opportunity to give and show precise information on chest pain of suspected cardiac origin which may have reduced the number of false positives.

During the campaign more patients called the central switchboard for medical emergencies as the first alert than before it. We chose to deliver the message "call 144" because such a strategy had previously proved to be associated with the shortest pre-hospital delays in our canton. ${ }^{12}$ Overall, ambulance use was not significantly modified. Ambulance use had already been found difficult to influence ${ }^{18}$; although there was no systematically collected information, partial reimbursement of ambulance fees by insurance companies may have influenced these results.

The cost-effectiveness ratios of public campaigns to reduce pre-hospital delays in suspected AMI have been modelled. ${ }^{24}$ These analyses suggest that bringing more patients with AMI to the emergency department may be cost effective, because such patients benefit from earlier monitoring and thrombolysis. In our study, thrombolysis or primary PTCA rates increased by an absolute $5.4 \%$, which was not a significant difference because of small numbers but which, if verified in larger scale studies, may have a profound impact on outcomes and long-term direct and indirect costs of AMI patients. The cost effectiveness ratios of public campaigns such as ours are very sensitive to the number of unnecessary department visits for chest pain of non-cardiac origin, and of unnecessary hospital admissions of such patients. ${ }^{24}$ During the Geneva campaign, the number of such visits or admissions was low.

The major limitation of our study is its observational design with two consecutive phases, rather than concurrent observation of two groups, one exposed to the campaign and the other not. The latter design would have been difficult to realise inside of Switzerland because our TV advertisements and messages were transmitted through the public TV network of all French speaking parts of the coun- try, and because the campaign was also picked up in the other linguistic regions. However, there are good reasons to think that the effects observed truly reflect the impact of the campaign, and not secular trends in Genevaspecifically the increase in the number of emergency department visits for chest pain during the campaign relative to emergency department visits for other medical or surgical conditions.

In conclusion, well targeted public campaigns may significantly reduce pre-hospital delays in patients presenting with AMI and unstable angina; despite transient increases in emergency department visits for non-cardiac chest pain, such campaigns may increase hospital visits for AMI and unstable angina and thus be cost-effective if coupled with stringent criteria for admission of patients with chest pain of non-cardiac origin. A policy of prehospital thrombolysis has not been implemented in Geneva because of the short ambulance transportation times previously recorded between the patients' houses and our emergency department (median time $8 \mathrm{~min}^{12}$ ). In rural areas or large cities where transportation may take time, campaigns such as ours could be coupled with pre-hospital thrombolysis administered by paramedics, emergency physicians, or trained general practitioners and could produce the survival benefits such as those shown by domiciliary thrombolysis in the Grampian Region, in Scotland. ${ }^{9}$

We thank Georges Kleinman, Jean-Marcel Schorderet, Sylvie Rossel, and Jean-Philippe Rapp, from the Télévision Suisse Romande, and Claude Froidevaux, from the Radio Suisse Romande, for their strong support during the campaign. This research was supported by grant from the Département de l'Action Sociale et de la Santé, Etat de Genève, Geneva, Switzerland. The public campaign was funded by the Assureurs Privés Suisses, the Swiss Heart Foundation, the Département de l'Action Sociale et de la Santé, and the Hôpital Cantonal Universitaire, Geneva, Switzerland.

1 Fibrinolytic Therapy Trialists' (FTT) Collaborative Group. Indications for fibrinolytic therapy in suspected acute myocardial infarction: collaborative overview of early mortality and major morbidity results from all randomized trials of more than 1000 patients. Lancet 1994;343:311-22.

2 The Gusto Investigators. An international randomized trial comparing four thrombolytic strategies for acute myocardial infarction. $N$ Engl $₹$ Med 1993;329:673-82.

3 Proceedings of the National Heart, Lung, and Blood Institute Symposium on rapid identification and treatInstitute Symposium on rapid identification and treatment of acute myocardial infarction. Issues and answers. Health Service, National Institute of Health, 1991.

4 Weston CFM, Penny WJ, Julian DG, on behalf of the British Heart Foundation Working Group. Guidelines British Heart Foundation Working Group. Guidelines
for the early management of patients with myocardial for the early management of patien
infarction. BMF 1994;308:767-71.

5 Greenberg H, Sherrid M, Lynn S, Dwyer E, O'Kelly J, Marsella R, et al. Out-of-hospital paramedic adminisMarsella $\mathrm{R}$, et al. Out-of-hospital paramedic administered streptokinase

6 Bouten MJM, Simoons ML, Hartman JAM, von Miltenberg AJM, van der Does E, Pool J. Pre-hospital thrombolysis with alteplase (rt-PA) in acute myocardial infarction. Eur Heart f 1992;13:925-31.

7 The European Myocardial Infarction Project Group. Prehospital thrombolytic therapy in patients with suspected acute myocardial infarction. $N$ Engl $f$ Med 1993;329: 383-9.

8 Weaver WD, Cerqueira M, Halstrom AP, Litwin PE, Martin JS, Kudenchuk PJ, et al. Prehospital-initiated versus hospital-initiated thrombolytic therapy. The Myocardial Infarction Triage and Intervention trial FAMA 1993;270:1211-6.

9 Rawles J, on behalf of the GREAT Group. Halving of mortality at 1 year by domiciliary thrombolysis in the Grampian Region Early Anistreplase Trial (GREAT). $\mathscr{f}$ Am Coll Cardiol 1994;23:1-5.

10 McCallum AG, Stafford PJ, Jones C, Vincent R, PerezAvila C, Chamberlain D. Reduction in hospital time to 
thrombolytic therapy by audit of policy guidelines. Eur Heart f 1990;11 suppl F:48-52.

11 National Heart Attack Alert Program Coordinating Committee, 60 minutes to treatment working group: emergency department: rapid identification and treatment of patients with acute myocardial infarction. Ann ment of patients with acute
Emerg Med 1994;23:311-29.

12 Gaspoz JM, Unger PF, Urban P, Chevrolet JC, Rutishauser W, Giacobino $\mathrm{H}$, et al. Délais dans la prise en charge et le traitement des patients avec suspicion d'infarctus aigu du myocarde: le rôle du public, des structures extra- et intra-hospitalières et des moyens de transport. Schweiz Med Wschr 1991;123: moyens

13 Rowley JM, Hill JD, Mitchell JRA. Early reporting of myocardial infarction: impact of an experiment in patient education. Br Med f 1982;284:1741-6.

14 Mitic WR, Perkins J. The effect of a media campaign on heart attack delay and decision times. Can $\mathcal{F}$ Public Health 1984;75:414-8.

15 Ho MT, Eisenberg MS, Litwin PE, Schaeffer SM, Damon SK. Delay between onset of chest pain and seeking medical care: the effect of public education. Ann Emerg Med 1989;18:727-31

16 Bett N, Aroney G, Thompson P. Impact of a national educational campaign to reduce patient delay in possible heart attack. Aust NZ f Med 1993;23:157-61

17 Rustiger JM, Burczyk U, Schiele R, Werner A, Senges J. Media campaign on delay times in suspected acute myocardial infarction. The Ludwigshafen Community Project (abstract). Eur Heart $\mathcal{f}$ 1990;11 suppl:171.

18 Herlitz J, Blohm M, Hartford M, Karlson BW, Luepker R, Holmberg $\mathrm{S}$, et al. Follow-up of a media campaign on delay times and ambulance use in suspected acute myocardial infarction. Eur Heart $f$ 1992;13 171-7

19 Herlitz J, Hartford M, Karlson BV, Risenfors M, Blohm M, Luepker RV, et al. Effect of a media campaign to reduce delay times for acute myocardial infarction and the burden of chest pain patients in the emergency department. den of chest pain patients in
Cardiology 1991;79:127-34.

20 Moses HW, Engelking N, Taylor GJ, Prabhakar C, Vallada $\mathrm{M}$, Colliver JA, et al. Effect of a two-year public education campaign on reducing response time of patients with tion campaign on reducing response time of patients with
symptoms of acute myocardial infarction. Am $f$ Cardiol 1991;68:249-251.

21 Eppler E, Eisenberg MS, Schaeffer S, Meischke H, Larson MP. 911 and emergency department use for chest pain: results of a media campaign. Ann Emerg Med

22 Multinational Monitoring of Trends and Determinants in Cardiovascular Diseases (MONICA Project). Manual of Operations (WHO/MNC/82.2), WHO, Geneva, 1983; 248.

23 Rutherford JD, Braunwald E. Chronic ischemic heart disease. In: Braunwald E, ed. Heart disease: a textbook of cardiovascular medicine. Philadelphia: Saunders, 1992; 1292-364.

24 Goldman L, Tosteson ANA. Cost-effectiveness of public education programs to reduce treatment delay in persons with ischemic heart disease. In: Proceedings of the National Heart, Lung and Blood Institute Symposium on rapid identification and treatment of acute myocardial infarction. Issues and answers. US Department of Health and Human Services, Public Health Service, National 